\title{
ESPAÇOS E CINEMA: OLHARES GEOGRÁFICOS PARA O MUNDO - RELATOS DE UMA EXPERIÊNCIA
}

\author{
Alberto Cristiano Pereira Santos ${ }^{1}$
}

\section{RESUMO}

Este artigo configura-se num relato de experiência produzido pelo discente idealizador e produtor executivo do projeto de extensão "Espaços e Cinema: Olhares Geográficos Para o Mundo", do Laboratório de Estudos Agrários e Urbanos (LEAU), atrelado ao Departamento de Geografia (DG), da Universidade Estadual do Sudoeste da Bahia (UESB), que desenvolveu ações de fomento ao diálogo entre o cinema e a geografia, através de atividades de formação de professores e alunos. O trabalho justifica-se pelo aumento substancial do uso dos recursos audiovisuais no estabelecimento dos processos de ensino-aprendizagem, tanto no âmbito da academia, quanto em escolas do ensino fundamental e médio da rede pública de educação. As ações, por sua vez, traduziram-se, concreta e objetivamente, em simpósios, mostras temáticas, exibições e debates de filmes, além de cursos e oficinas, que se nortearam sempre pelo desejo de possibilitar aos agentes envolvidos nos processos de formação acadêmica e/ou escolar, uma inicialização à interface geografia $\mathrm{x}$ cinema x educação, bem como, a democratização do acesso à diversidade da produção cinematográfica. Ainda devemos acrescentar o despertar de interesse pela $7^{\circ}$ arte em crianças e adolescentes. A partir dessas práticas extensionistas, observou-se a importância de algumas nuances do projeto, tais como o embrionamento e consolidação do diálogo cinema x geografia, o estabelecimento de critérios para utilização da linguagem cinematográfica

\footnotetext{
${ }^{1}$ Graduando em Licenciatura Plena em Geografia pela UESB e Coordenador do Projeto de Extensão "Espaços e Cinema: Olhares Geográficos para o Mundo" (Financiado pela UESB). Laboratório de Estudos Agrários e Urbanos (LEAU). E-mail: ruivogeocinema@gmail.com
} 
em salas de aula, além da importância da formação teórico-instrumental dos estudantes atendidos pelo projeto.

Palavras-chave: Cinema. Educação. Ensino. Geografia.

\title{
SPACES AND CINEMA: LOOKS FOR GEOGRAPHIC WORLD - EXPERIENCED ACCOUNTS
}

\begin{abstract}
This article sets up an experience report produced by the creator and executive producer of the student outreach project "Spaces and Cinema: Geographical Perspectives To The World", Laboratory of Land and Urban Studies (LEAU), linked to the Department of Geography (DG) State University of Southwest Bahia (UESB), which developed initiatives to foster dialogue between cinema and geography, through teacher training and student activities. The work is justified by the substantial average increase in the use of audiovisual aids in establishing the processes of teaching and learning, both within the academy, as for elementary schools and public education. Actions, in turn, translated into concrete and objectively, in symposia, thematic exhibitions, displays and discussions of films, as well as courses and workshops, which have always guided by the desire to enable stakeholders in the processes of academic and / or school, an initialization interface geography $\mathrm{x}$ film education as well as the democratization of access to the diversity of filmmaking, besides awakening of interest in the 7th art in children and adolescents. From these extensionists practices, noted the importance of some nuances of the project, such as embryonation and consolidation of dialogue film $\mathrm{x}$ geography, the establishment of criteria for use of film language in the classroom, and the importance of theoretical training -instrumental students served by the project.
\end{abstract}

Keywords: Cinema. Education. Teaching. Geography.

\section{Introdução}

Esta análise é resultado do trabalho desenvolvido por um dos idealizadores e organizadores do projeto de extensão "Espaços e Cinema: Olhares Geográficos Para o Mundo - Anos 1, 2 e 3", atrelado ao LEAU, do Departamento de Geografia da UESB - campus de Vitória da Conquista. O relato que se segue discorre acerca do uso dos 
recursos audiovisuais, especificamente, do cinema, no estabelecimento de processos de ensino-aprendizagem e pretende encontrar subsídios, primeiro, para afiançar novos critérios na utilização desta linguagem em sala de aula, e, segundo, para garantir maior aproximação destes recursos aos saberes e conteúdos geográficos. Constitui fato consumado o aumento do trabalho docente relativo à utilização do cinema como instrumento didático passível de uso na transmissão dos conteúdos programáticos particulares às várias disciplinas e campos do saber. $\mathrm{Na}$ mesma proporção, são muitos os esforços em reverter esta postura equivocada de boa parte da docência, que ora emprega o cinema em sala de aula como forma de recreação, ora emprega de maneira didatizada. Nesse sentido, observa-se um grande número de pesquisadores somando esforços para que, por meio de atividades reflexivas e práticas, o cinema possa ser introduzido no âmbito educacional enquanto expressividade, isto é, como um largo horizonte de possibilidades que permitam a experiência estética, traduzindo-se em algo desejável pelos sujeitos da academia e escola, ou seja, algo significativo para eles.

A metodologia do projeto aqui relatado se deu por intermédio de simpósios, exibições e debates de filmes, cursos, oficinas e mostras temáticas que enfocaram a possibilidade de encontro entre temas e conhecimentos caros à ciência geográfica e às várias escolas do cinema mundial, bem como a problemática da linguagem cinematográfica na construção de outras formas de ler, pensar e fazer geografia.

Num primeiro momento, com o intuito de atestar as possibilidades de tal diálogo, as ações do projeto buscaram fomentar o debate por meio da realização de mostras temáticas e simpósios. Essas atividades, por sua vez, reuniram estudantes, profissionais e pesquisadores da geografia nacional, que, a partir de reflexões e leituras coletivas de obras fílmicas, construíram um arcabouço de ideias para subsidiar a análise geográfica em simbiose com o cinema. Dessa forma, temas muitas vezes reservados à geografia, tais como crime e violência no campo e na cidade, a relação capital x trabalho, globalização e regionalização do mundo contemporâneo, ou os novos arranjos territoriais brasileiros e a inserção 
do Nordeste neste processo, passaram a ser observados sob o prisma da linguagem cinematográfica.

Já num segundo momento, objetivou-se ampliar os horizontes que tangenciam a utilização do cinema em processos formativos nas escolas. Através da realização de cursos, cujo público alvo era os professores de escolas da rede pública de ensino, buscou-se desconstruir a ideia do cinema na condição de instrumento viabilizador da transmissão dos conteúdos programáticos, rompendo assim com a perspectiva didatizadora da sétima arte. A problemática compunha-se em instituir o entendimento das obras fílmicas para além da racionalidade instrumental, extrapolando as obrigações estritamente formais dos aprendizados escolares e conteúdos disciplinantes a serem estudados em sala de aula.

Por fim, visando o contato com a linguagem cinematográfica desde as séries iniciais até o ensino médio, o projeto desenvolveu oficinas de produção de vídeo em animação e de vídeo documentário, além de exibições públicas de filmes, como maneira de buscar a formação teórico-prática em crianças e adolescentes na área do cinema e audiovisual. Tal vertente fornecia, ainda, elementos discursivos que também estimulavam a ideia da necessidade de transformação no modo como o cinema vem tangenciando os processos de ensino-aprendizagem.

Durante a execução das atividades supracitadas, foram realizadas conversas com os participantes a fim de elaborar um cabedal de informações acerca de seus conhecimentos sobre cinema e geografia, bem como sobre a relação entre as diversas produções e formatos cinematográficos e os olhares sobrevindos dos conhecimentos fornecidos pelas ciências humanas, principalmente pela geografia. A abordagem incluía discussões sobre a história do cinema brasileiro e mundial; o desenvolvimento do cinema e as transformações sociais durante $\mathrm{O}$ século XX; as novas possibilidades da produção cinematográfica com o advento das tecnologias digitais; o uso do cinema nos processos de ensino-aprendizagem; os padrões de sociabilidade na era moderna; as características da produção capitalista do espaço (escassez do trabalho, radicalização da violência nos espaços urbanos e rurais; a banalização 
da barbárie social etc.); o meio ambiente e os problemas ambientais no mundo globalizado; e a histórica relação capital x trabalho.

Em vista dos trabalhos realizados, sejam no campus da Universidade, ou nas escolas dos municípios visitados (Vitória da Conquista, Belo Campo e Caraíbas), observou-se uma prática preocupante que confirma a falta de critérios por parte dos docentes para se trabalhar com a linguagem cinematográfica em sala de aula. Nesse mesmo sentido, percebeu-se, sobretudo no meio discente, o quanto o conceito de cinema é restrito e empobrecido, quase sempre atrelado aos formatos hollywoodianos e a ideia de entretenimento.

Retomar algumas reflexões que solucionem essas dificuldades, colocando em debate questões e desafios que afligem o uso da sétima arte em escolas ou na academia, no sentido de transformar o atual cenário de práticas equivocadas numa perspectiva pedagógica em que o cinema se configure em método e possibilidade de processo de ensinoaprendizagem dos saberes e conhecimentos geográficos, tornou-se o desafio para o projeto em questão.

\section{Desenvolvimento}

Desde os primórdios o homem se empenha no trabalho de representar seu cotidiano ou fatos marcantes dele. Dessa maneira, vale concordar que as manifestações visuais no trajeto da humanidade remontam os tempos pré-históricos. Para se ter ideia, as primeiras evidências da importância da imagem nos processos de significação e representação do homem são os desenhos e pinturas rupestres. Assim, podemos afirmar que esses desenhos e pinturas configuram verdadeiro exercício da percepção do homem e da sua capacidade de exteriorização simbólica. Nesse sentido, podemos atestar que ao longo do seu processo histórico civilizatório, o homem elaborou um vasto universo de linguagem expressa em imagens que atravessam desde os desenhos nas cavernas e esculturas em barro até a arquitetura, a fotografia e, no final do século XIX, também o cinema. 
$\mathrm{Na}$ esteira desse processo, pode-se constatar, ainda, que as imagens em movimento - possibilitadas graças à invenção do cinematógrafo pelos irmãos August e Louis Lumière em 1985 - provocaram um impacto sem precedentes na constituição dos modos de ser do homem moderno. Justamente por isso, essas imagens em movimento, especificamente as veiculadas pelo cinema, não escaparam aos interesses de estudos das ciências sociais e humanas. Deste modo, a arte cinematográfica e suas práticas tornaram-se temas de inúmeros campos do saber, dentre eles, a geografia.

No cotidiano atual, por sua vez, vivencia-se um verdadeiro espetáculo imagético, levando a corroborar com a ideia de que a imagem aparece na atual realidade sócio-espacial como um dos instrumentos reinantes no que tange à produção e reprodução de sentidos e modos de ver/entender o mundo. Toda experiência sócio-espacial da sociedade contemporânea está marcada pela aceleração do ritmo de produção e reprodução da imagem.

Por conseguinte, são diversos os geógrafos e autores de diferentes áreas do saber que explicitam o valor da imagem em geral e, especificamente, do meio cinematográfico, como foco de estudo incontornável para se compreender a sociedade e suas contradições. As práticas estéticas e culturais, sobretudo as imagéticas, possuem particular sensibilidade para captar o movimento cambiante do espaço e do tempo, uma vez que estão envolvidas com a construção de representações que sinalizam experiências localizadas no processo histórico-espacial do homem.

Com o trabalho desenvolvido pelo projeto "Espaços e Cinema: Olhares Geográficos Para o Mundo", almejou-se considerar tal influencia da imagem, especificamente das que substancializam a linguagem cinematográfica, evidenciando sua interlocução com os processos formativos, de construção de valores e de assentamento dos padrões de sociabilidade moderna.

Adjacente a tal perspectiva, a linguagem cinematográfica passou a ser interpretada como possibilidade de contato, compreensão, criticização 
e negação - esse último, em seu sentido dialético - das transformações sociais em curso na sociedade contemporânea, confrontando a práxis que comumente encontra-se em exercício nos ambientes escolares, a saber, a didatização do cinema em sala de aula ou, numa radicalização desse quadro, a mera instrumentalização ou simplificação dos recursos audiovisuais.

Por meio de conversas com os professores das escolas que firmaram parceria com o projeto, pôde-se constatar que há um numero significativo de práticas docentes que abordam seus conteúdos programáticos a partir da utilização de filmes, no entanto não existe nenhum tipo de orientação no sentido de trabalhar a sétima arte como prolongamento da construção dos sujeitos sociais. Daí a necessidade do estabelecimento de determinados critérios para o uso da linguagem cinematográfica, que a eleve à condição de processo de ensinoaprendizagem:

O cinema deve estar na escola não como um conteúdo curricular e campo de especialidade de um professor, mas [...] em outra perspectiva, fugindo à racionalidade instrumental e às obrigações estritamente formais dos aprendizados e conteúdos. Trata-se, ao invés, de um encontro com o cinema como expressividade, como um largo horizonte de possibilidades que permitam a experiência estética, algo significativo para os sujeitos da escola (AZEVEDO; TEIXEIRA, 2011, p. 14).

Tal referência, por sua vez, repercute como negação à geografia escolar que se coloca em prática na atual conjuntura do ensino brasileiro. Embora a geografia encontre, hoje, grande unidade em sua escola crítica, manifestando seus conteúdos segundo uma postura de oposição à realidade social e espacial, contraditória e injusta, fazendo dos seus conhecimentos uma arma de contestação à realidade concreta e objetiva existente, o que se observa no contexto da geografia escolar é a reprodução de práticas alicerçadas em paradigmas reducionistas e mecanicistas que muito caracterizam essa ciência até a segunda metade do século XX. 
Além dessas questões, o projeto procurou discutir a consolidação do espaço de debate sobre a dimensão espacial da realidade apresentada pela ótica cinematográfica e sobre a importância e possibilidades do trabalho da análise geográfica (docente ou não) mediado pelo cinema. O objetivo foi promover uma relação de ensino-aprendizagem capaz de permitir aos agentes envolvidos nos processos educacionais o desenvolvimento de novas metodologias de trabalho em sala de aula, que possibilitassem a interação entre a experiência acumulada na trajetória do docente e o saber construído ao longo da vivência dos estudantes.

A repercussão dessa aproximação entre a linguagem cinematográfica e a geografia vai além do embrionamento de novos espaços de debate sobre a realidade a partir de obras fílmicas. Pensar em critérios que viabilizem o cinema adentrar a sala de aula como processo de ensino-aprendizagem, ou seja, como encontro com a alteridade, e, por conseguinte, refletir sobre o estabelecimento do contato entre a leitura do geógrafo e do que é desenvolvido no ensino de geografia e as possibilidades inesgotáveis de ações com caráter interdisciplinar que o cinema traz para os processos educativos, permite ao público atendido pelo projeto elaborar, a partir de suas praticas cotidianas e experiências de vida, novos modos de experimentar, refletir e objetivar o espaço e o tempo, repercutindo assim, em novas formas de ler, teorizar e fazer geografia.

\section{Metodologia}

Este relato de experiência é produto do trabalho realizado ao longo de três edições do projeto de extensão "Espaços e Cinema: Olhares Geográficos Para o Mundo", proposto pelo LEAU e financiado pela Pró-Reitoria de Extensão e Assuntos Comunitários (PROEX), da UESB. Inicialmente, para as atividades promovidas dentro do campus da universidade cujo público alvo estendia-se a toda comunidade acadêmica, foram realizadas reuniões com professores da casa para viabilizar a promoção tanto de mostras temáticas de filmes quanto de simpósios acadêmicos. O mesmo procedeu-se com professores 
de outras instituições de ensino superior do país, como Universidade Federal do Rio de Janeiro (UFRJ), Universidade Federal da Paraíba (UFPB), Universidade Federal de Sergipe (UFS), Universidade Estadual do Estado de São Paulo (UNESP) - Presidente Prudente.

Os temas das mostras temáticas foram "Crime e Violência no Campo e Cidades Brasileiras", "Movimentos Sociais e Geografia" e "Globalização". A dinâmica correspondia à leitura coletiva de filmes alinhados às temáticas supracitadas, acompanhadas de análise de um ou mais professores, estudantes e pesquisadores peritos no tema, seguido de um debate no sentido, não de esgotar as discussões, mas, notadamente, de abrir novas possibilidades de interpretação e entendimento para o assunto. Ao final, era proposto a $25 \%$ dos participantes o preenchimento de um questionário em que se avaliava o desempenho dos comentaristas, a qualidade dos filmes exibidos e a pertinência dos mesmos.

No que diz respeito aos simpósios acadêmicos, foram realizados dois: um no ano de 2012, com o tema " $1{ }^{\circ}$ de Maio no Cinema: Capital x Trabalho na Linguagem Cinematográfica”, e outro em 2013, circunscrevendo o tema "Nordeste Brasileiros: Os (RE)arranjos Territoriais da Região Nordeste do Brasil”. Em ambos, os participantes receberam folders e panfletos contendo as principais informações dos eventos, além da programação dos mesmos, com o detalhamento do que seria discutido em cada um dos espaços propostos - mesas redondas, lançamentos de livro, exibições e debates de filmes, minicursos e oficinas -, bem como horários e locais das atividades. Ao final dessas ações, também foi proposto a $25 \%$ dos participantes o preenchimento de um questionário que avaliava de maneira geral os eventos, possibilitando a sugestão de novos temas, dinâmicas e metodologias.

Num outro momento, quando as atenções do projeto se voltavam para o publico externo à academia, a saber, pessoas interessadas em cinema, além de professores e estudantes da rede pública de ensino dos municípios de Vitória da Conquista, Belo Campo e Caraíbas, foram desempenhadas uma série de ações formativas e de instrumentalização teórica e técnica, que se traduziram em cursos, oficinas e sessões de cinema. 
Os cursos ministrados por pesquisadores da área de cinema e educação aconteciam em classes com aulas expositivas ministradas em quadro branco e com o auxílio de apresentação de conteúdos em power point, acompanhados do estudo de material didático distribuídos aos participantes (apostilas produzidas pelos ministrantes e artigos científicos), da leitura coletiva de obras fílmicas ou de trechos dos mesmos e da realização de dinâmicas em grupo, que analisavam e discutiam os conteúdos apresentados, tendo como resultados o esclarecimento da relação cinema x educação, culminando no estabelecimento de critérios para a utilização do cinema como processo de ensino-aprendizagem.

As oficinas, por sua vez, eram oferecidas aos estudantes matriculados nas escolas visitadas e variavam de acordo com a faixa etária dos mesmos. Para alunos com idades entre 9 e 12 anos, era oferecida a "oficina de sensibilização do olhar para o cinema", que consistia na exibição de curtas e longas metragens e aulas recreativas que colocavam as crianças em contato com o universo cinematográfico, tendo como produto painéis e mosaicos produzidos a partir de recortes, colagens e sobreposições de matérias como glitter, pó de serra e serpentina em cartolinas ou papel madeira.

Com os estudantes de 13 a 15 anos de idade, era desenvolvida a oficina de animação. A metodologia consistia na apresentação de conteúdos em powver point e exibições de filmes, que trabalhavam o entendimento das técnicas de stop motion (que trata de dar "vida" a seres inanimados a partir de retirada de fotos em planos de sequência). Nessa atividade, os estudantes tinham a possibilidade de participar de dinâmicas de grupo que os colocavam diante da interação, em tempo real, com técnicas de captação de imagens (a partir da utilização de câmeras fotográficas disponibilizadas pelo projeto ou com a utilização dos próprios celulares dos educandos) e, ainda, de edição de imagens (com o uso de computadores com softwares específicos para tal trabalho). Além disso, os participantes eram estimulados a exercitar sua capacidade lúdica com a criação dos roteiros, das historias, dos personagens e, principalmente, com a produção dos cenários, que eram fabricados a partir de materiais como palitos de picolé e de dente, 
algodão, brinquedos, caixas de papelão, massinha de modelar e todo tipo de papel celofane, crepom, oficio, madeira, etc.

Num outro espaço, estimando atender os alunos com idade acima de 16 anos, o projeto propunha uma oficina de produção de vídeo e documentário. Ministrada por um profissional com experiência na produção de obras premiadas até mesmo fora do país, com o auxilio de uma discente do curso de cinema e audiovisual da UESB, essa oficina detinha uma metodologia muito próxima das citadas anteriormente. Com a apresentação em power point, acompanha da analise de material didático disponibilizado pelo projeto e com a leitura coletiva de obras fílmicas, os participantes puderam vislumbrar conteúdos que abordavam temas como a função do cinema e do vídeo; as diferenças entre essas duas vertentes do audiovisual; as noções de construção de roteiro; o som e os sentidos no cinema; filmagem, edição e montagem; bem como as formas de exibição e distribuição de vídeos e documentários. Na pratica, essa oficina se traduzia na formação de grupos que ficavam responsáveis pela confecção, em mídias de DVD, de um vídeo-documentário ficcional ou real, que envolvia a definição de uma história, a criação de um roteiro, além da filmagem, edição e montagem.

Ao final das oficinas de animação e de produção de vídeo e documentário, eram disponibilizados questionários aos participantes, com perguntas referentes à metodologia, conteúdo, referencial teórico e dinâmica utilizados no desenvolvimento das atividades, além da pontualidade e desempenho da equipe executora das ações extensionistas, contendo, ainda, um espaço para críticas e sugestões.

Por fim, em cada uma das escolas visitadas, o projeto promovia exibições públicas de filmes num clima consideravelmente descontraído, com a apresentação de obras nacionais curtas e longa metragem em formato semelhante ao das salas de cinema. Toda a população da localidade visitada era convidada a participar, promovendo uma interação pertinente entre universidade, escola e comunidade, que acabava por despertar nos indivíduos o interesse pela sétima arte e, principalmente, $\mathrm{o}$ interesse em atividades de caráter educativo e cultural. 


\section{Conclusão}

É indubitável a presença dos recursos audiovisuais nas instituições de ensino de todo o país, sejam elas de educação de nível básico ou superior. Além de constatar tal afirmativa, as atividades do projeto de extensão "Espaços e Cinema: Olhares Geográficos Para o Mundo" trouxeram notoriedade para o aumento substantivo do uso destes recursos, principalmente, do cinema em sala de aula.

Neste contexto, porém, percebeu-se uma série de equívocos nas perspectivas de abordagem desta que se configura como a sétima arte. Ora implementado como recuso didático, ora como momentos de recreação ou "tapa janelas", o cinema na escola ou na universidade em muito pouco vem sendo trabalhado como possibilidade de um processo de ensino-aprendizagem que formule pedagogias de ensino verdadeiramente significativas para os estudantes e professores.

Estabelecer critérios para elevar o cinema à categoria de linguagem em processos de ensino-aprendizagem em sala de aula, bem como expandir os horizontes do olhar para a sétima arte em crianças, adolescentes e jovens estudantes, por meio de atividades que os coloquem em contato não somente com o ler, mas, sobretudo, com o fazer cinema; e ainda, democratizar o acesso a essa arte para o maior número de pessoas possível, apresentando ao público a riqueza da produção cinematográfica nacional, foram desafios estimados e alcançados pela equipe executora do projeto.

Por conseguinte, é possível afirmar que a ação extensionista em relato proporcionou também aprendizado e desenvolvimento significativos para os membros executores das atividades, sobretudo aqueles cuja área de estudos circunscreve a geografia.

O fio norteador do projeto, materializado por meio de suas ações, leva ao estabelecimento da relação entre a leitura do geógrafo - e do que é desenvolvido no ensino de geografia - e a capacidade de entendimento desses como realidade concreta, seja pelos membros da equipe executora, seja pelo público atendido. O espaço, tantas 
vezes refletido e teorizado pelos geógrafos e estudantes, é, a partir do desenvolvimento das ações do projeto, colocado como espaço real a ser trabalhado. Nessas condições, não mais se estabelece como abstração algo que se pensa e estuda apenas - mas como externalidade de onde se obtêm os parâmetros para formular os projetos de pesquisa e seus objetos, bem como os projetos de extensão e suas prioridades.

Consolidar o diálogo entre cinema e geografia em uma prática extensionista, portanto, faz com que não apenas os processos de ensinoaprendizagem estabelecidos pela linguagem cinematográfica sejam (re) pensados e emancipados, como também a geografia acadêmica ou escolar que vem sendo construída, pois serve como contextualização dos conceitos e das categorias que são objetos de estudo desse campo do saber.

\section{Referências}

AZEVEDO, Ana Lucia de Faria; TEIXEIRA, Inês Assunção de Castro. Os professores e o cinema na companhia de Bengala. In: FRESQUET, Adriana. Dossiê Cinema e Educação \# 2. Rio de Janeiro: Booklink; CINEAD-LISE-FE/UFRJ, 2011. p. 13-34.

BARBOSA, Jorge Luiz. A arte de representar como reconhecimento do mundo: o espaço geográfico, o cinema e o imaginário social. Revista GEOgraphia, ano 2, n. 3, 2000.

BARBOSA, Jorge Luiz. Geografia e Cinema: em busca de aproximações e do inesperado. In: CARLOS, Ana Fani A. (Org.). A geografia em sala de aula. São Paulo: Contexto, 1999.

GEIGER, Pedro P. Ciência, Arte e a Geografia no cinema de David Lynch. GEOUSP - Espaço e Tempo, São Paulo, n. 15, 2004.

MACIEL, Caio Augusto Amorim; FILHO, Pedro Paulo Pinto Maia. Geografia e Cinema: paisagens e imagens do semi-árido nordestino. Revista Eletrônica Tempo - Espaço - Território, v. 2, n. 1, 2006. 